\title{
SUPPORT OF THE CIRCULATION BY MECHANICAL MEANS:
}

\section{A REVIEW}

\author{
D. Evans, M.B., CH.B., F.R.C.P.(c)
}

Simple meChanical procedures for supporting the circulation have been used in and out of the operating room environment for many years. Even the lay public have become aware of, and use, such methods as external cardiac massage and the head down tilt for resuscitation. Until recently the more sophisticated devices have been reserved exclusively for use in the operating room. However, due to a much more positive ${ }^{1}$ approach to the problem of cardiovascular support in emergencies, their use in intensive care units, and even on the ward, has led to a widening interest in the different types of devices and methods available. Anaesthetists, due to their unique objectivity and knowledge of respiratory and cardiovascular pathophysiology, are spending varying periods of their time away from the operating room to become involved in intensive care or resuscitation. The term "intensivist" has now become an established part of the anaesthetic jargon and is an indication of the changing role of the anaesthetist. Because of this, I wish briefly to review the types and methods of mechanical support of the circulation with some of their respective advantages and disadvantages. Some of these methods are available in all hospitals, some at only the larger university institutions; some are simple, but most are quite complicated; some are relatively cheap to operate and some so expensive with regard to personnel required and cost of apparatus that one wonders whether there is any real economic validity in their use at the present time.

Crassification of Methods of Assisted Circulation:

1. Direct Mechanical Assistance of the Left Ventricle

(a) External Cardiac Massage

(b) Internal Cardiac Massage

2. Indirect Mechanical Assistance of the Left Ventricle
(a) Tilting
(b) Mechanical Ventilation
(c) Left Ventricular Bypass
(d) Counterpulsation
(e) Auxiliary Ventricle
(f) Veno-Arterial Bypass

\section{Miscellaneous}

(a) Aortocoronary Perfusion

(b) Veno-Venous and Arterio-Arterial Oxygenation

(c) Mechanical Heart 


\section{Direct Mecilanical Assistance of the Left Ventriclf:}

\section{(a) External Cardiac Massage}

This method has been in use for well over one hundred years ${ }^{2-4}$ but its re-discovery some ten years ${ }^{5}$ ago has led to its widespread use in and out of the hospital environment. Investigations ${ }^{6-9}$ show that it can produce, at best, flow rates somewhat below control; at worst, pulmonary oedema, probably due to high left atrial pressures. It is useful only for relatively short periods of time due mainly to the traumatic effect of the procedure and the physical effort required by the persons applying it. The latter factor can, however, be alleviated by the use of teams or a mechanical massage device.

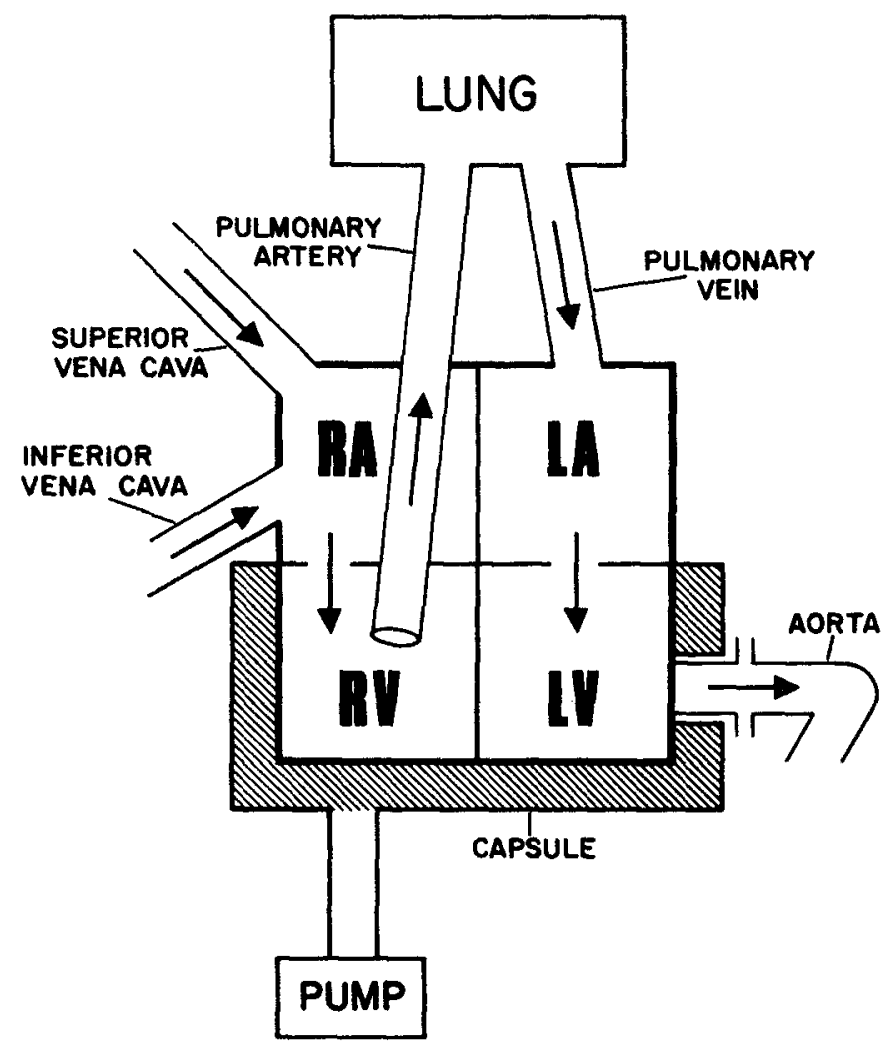

Figure 1. Mechanical internal cardiac massage: inflatable capsule surrounding left and right ventricles.

\section{(b) Internal Cardiac Massage}

Manual internal cardiac massage is almost of historical interest, except in instances where the chest is already open, such as during pulmonary or cardiac surgery. However, mechanical devices have been designed and tested ${ }^{10-13}$ in animals with some success. One of these (Figure 1) consists of a pneumatically inflated capsule surrounding the heart in which the pressure can be raised and lowered by 
means of a pump. The technical problems, besides that of the major surgery, are many and preclude the use of this kind of device in the clinical situation at the moment. The advantages cited are that both ventricles are supported ${ }^{\mathbf{1 0}}$ and the patient's blood does not pass through any extra vascular pumping device. Recent work $^{14}$ shows that the blood flow to vital organs is well maintained and in some instances raised above control values.

\section{2. indirect Mechanical Assistance of the Left Ventricle}

\section{(a) Tilting}

Tilting the body either head up or head down will cause changes in hydrostatic pressure and thereby affect cardiac output. The principles involved are, of course, those enunciated many years ago ${ }^{\mathbf{1 5 , 1 6}}$ and known as "Starling's Law of the Heart." Although now a little controversial, ${ }^{17-20}$ the law still remains a good working hypothesis. An increase in right atrial or right ventricular end-diastolic pressure leads to an increase in cardiac output, a decrease in these pressures will lead to an opposite effect. If the pressures in these chambers go above a certain point, however, cardiac output will decrease due to overstretching of myocardial muscle fibres. Tilting head down will, therefore, improve cardiac output in acute hypovolaemic states, such as haemorrhage. Head up tilt will improve cardiac function in decompensated heart failure by decreasing right atrial and right ventricular end-diastolic pressure.

\section{(b) Mechanical Ventilation}

Changes in the intra-thoracic positive and negative pressures will change cardiac output and myocardial function. Increase in negativity will decrease the pressure in the right atrium and cause an increase in the venous return and cardiac output. However, due to many factors, but mainly to the collapse of the veins entering the thorax, there is a limit to the increase in cardiac output obtainable and, in fact, the overall effect is relatively slight. ${ }^{21,22}$ An increase in intra-thoracic positive pressure ${ }^{22,24}$ on the other hand, causes marked change, and will lead, in the hypovolaemic patient, to a marked decrease in venous return and cardiac output. However, in cases of myocardial decompensation it will cause decreased distention of the right ventricle and improvement in myocardial function.

\section{(c) Left Ventricular Bypass}

(i) Through Peripheral Vessels. To avoid the surgical trauma of a thoracotomy, a method has been devised ${ }^{25}$ by which a cannula is passed through the jugular vein into the right atrium and then through the septum into the left atrium (Figure 2). Blood is taken from the left atrium and pumped in a retrograde fashion up the aorta. A variation of this method ${ }^{26}$ involves passing the cannula up the brachial artery and into the left ventricle from whence the blood is withdrawn. The object of these methods is to reduce the cardiac output to such a level that the left ventricular work load and oxygen consumption become extremely small. The decrease in cardiac output necessary to obtain an appreciable reduction in these factors has been somewhat controversial. There is some experimental evidence ${ }^{27,28}$ that the cardiac output must be reduced by at least 95 per cent to cause any real reduc- 


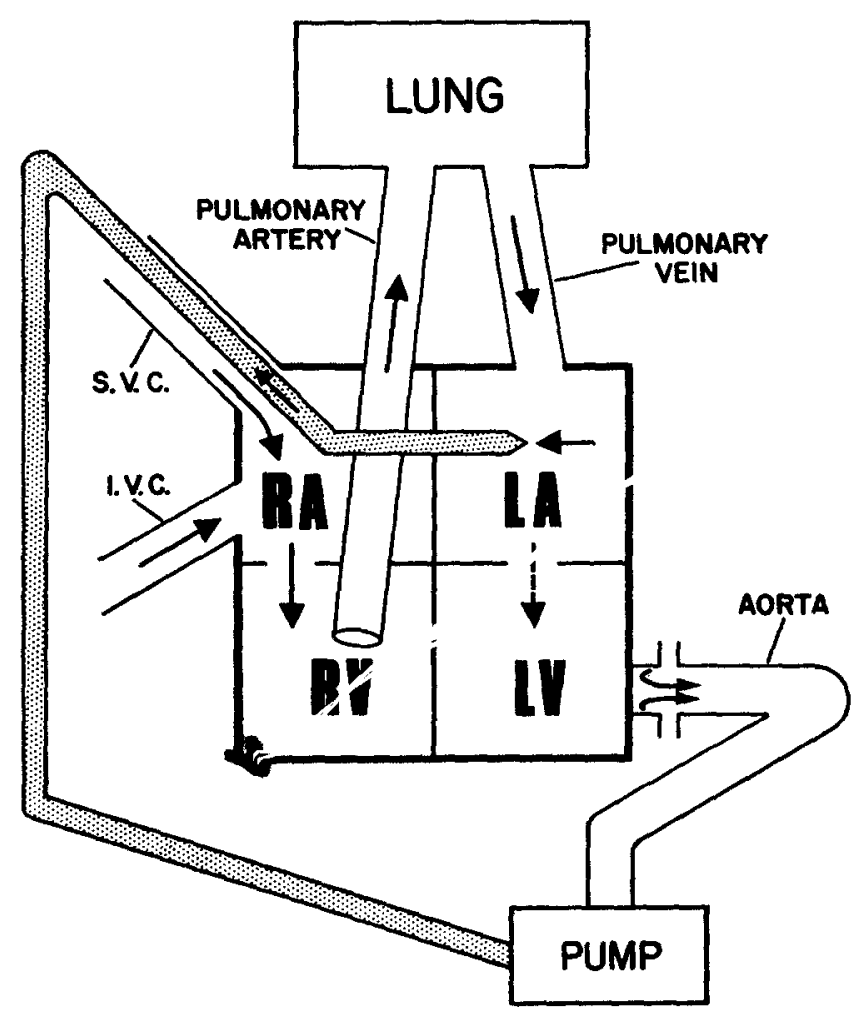

Figure 2. Left ventricular bypass through peripheral vessels: cannula in left atrium withdrawing left atrial input.

tion in left ventricular work and oxygen consumption. This, however, has not been the experience of others workers. ${ }^{29}$ If we take the 95 per cent figure to be correct, the withdrawal of blood from the left atrium in the first method would have to be almost complete. Experimentally this has been shown ${ }^{28}$ to be true in the initial period of bypass anyway. Clinically, no assessment has been made of the percentage of the left atrial inflow which passes out through the cannula. Insertion of the cannula is technically difficult with considerable risk involved.

(ii) By Thoracotomy. This type of support is routinely used during open heart surgery. Cannulae are placed in the inferior vena cava and superior vena cava and the vessels around them are occluded with tape (Figure 3). These cannulae collect the venous return from all parts of the body except the myocardium and the lung tissue and the blood is then passed through an oxygenator and pumped through the femoral artery in a retrograde fashion up the aorta. Loosening the tapes around the superior and inferior vena cava produces the so-called "partial bypass." During partial bypass a portion of the venous return gains entry to the right atrium and is passed around the body in the normal fashion. It allows the left ventricle to be exposed to a gradually increasing work load and obviates the sudden on/off pump situation. However, from the evidence quoted ${ }^{27,28}$ in the previous section, one wonders whether, in fact, the myocardium can ever be ex- 


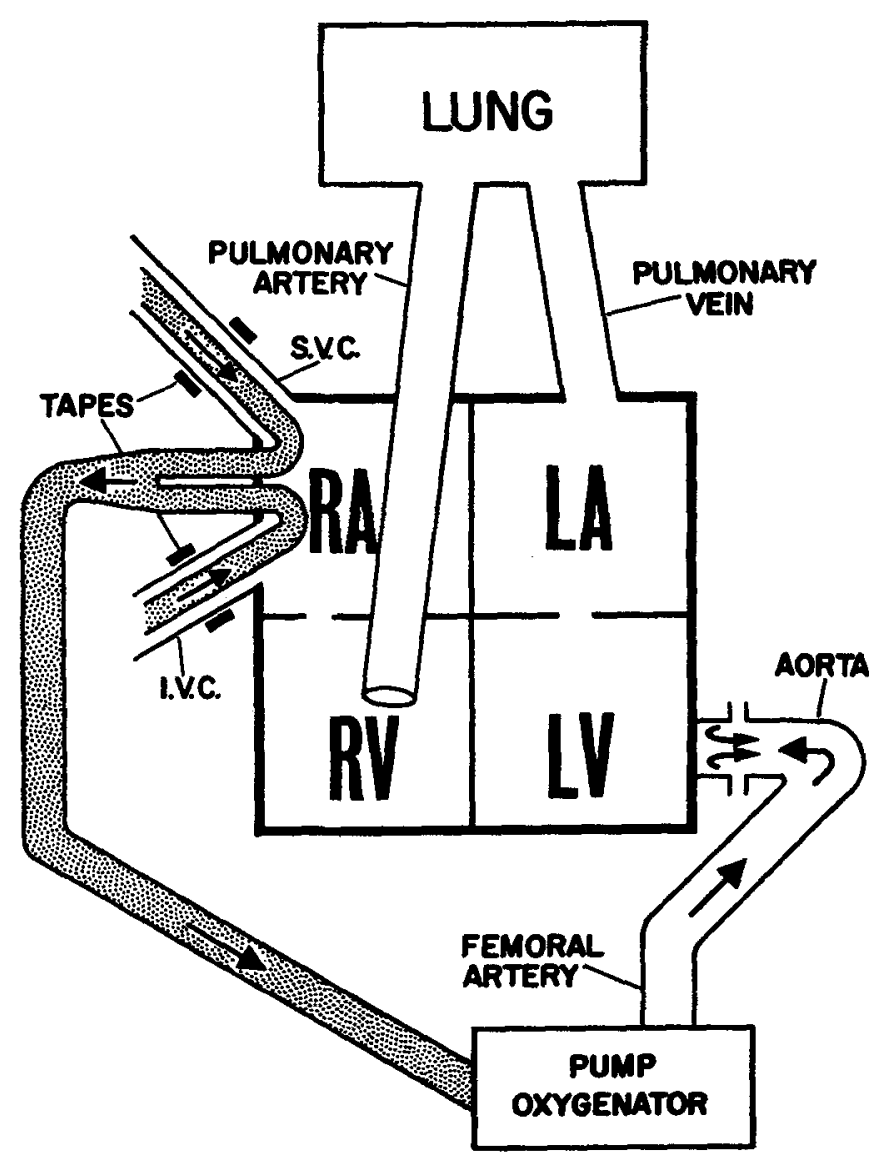

Figure 3. Left ventricular bypass via thoracotomy: venous return collected by cannulae in inferior and superior venae cava.

posed to a gradual increasing work load seeing that a diastolic filling volume of only 5 per cent of normal increases the work load and oxygen consumption considerably. Notwithstanding this evidence, however, in the clinical situation it certainly seems to smooth the change-over from total bypass to normal circulatory function. Because of the surgical trauma involved in setting up this kind of circulatory assistance, it is only used in the operating room environment for definitive surgical procedures.

\section{(d) Counterpulsation}

(i) Arterio-Arterial. This method involves sucking blood out of the aorta just before and during ventricular systole and pumping it back during diastole ${ }^{30,31}$ (Figure 4). This decreases the pressure against which the heart has to jump during systole and thereby decreases left ventricular work and oxygen requirements. ${ }^{32,34}$ During diastole blood is returned to the aorta and the increase in pressure during this period increases coronary flow. ${ }^{35,36}$ The problems associated with this device are those inherent in any method involving the passage of blood rapidly 


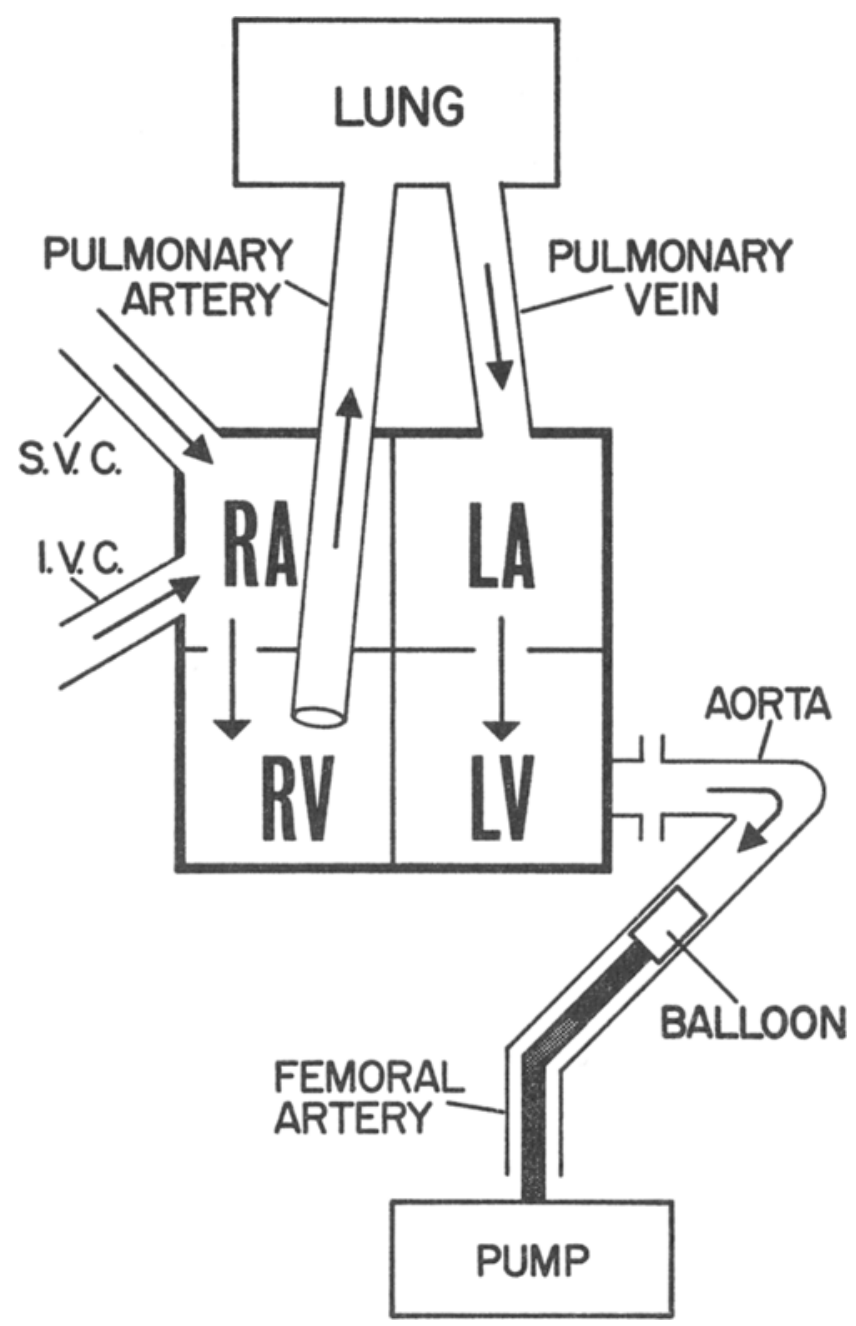

Figure 4. Counter pulsation: arterio-arterial cannula in lower aorta sucks blood in during left ventricular systole, pumps it back during diastole.

in and out of relatively small cannulae. One of these problems is the purely technical one of inertia, associated with any fluid with the physical properties of blood. Another is trauma to the blood elements leading to haemolysis. ${ }^{36} \mathrm{~A}$ further problem $^{37}$ which is not associated with this type of mechanical device alone, is synchronization of the pump with the electrocardiogram. This may be extremely difficult, especially in the presence of arrhythmias. Clinical experience with this method has not been wide, but experimentally in dogs it has been found ${ }^{30}$ that survival rates can be improved by up to 100 per cent. There is an increase of coronary flow of up to 50 per cent, a decrease of myocardial work of 70 per cent and a decrease in myocardial oxygen consumption of 20 per cent. 


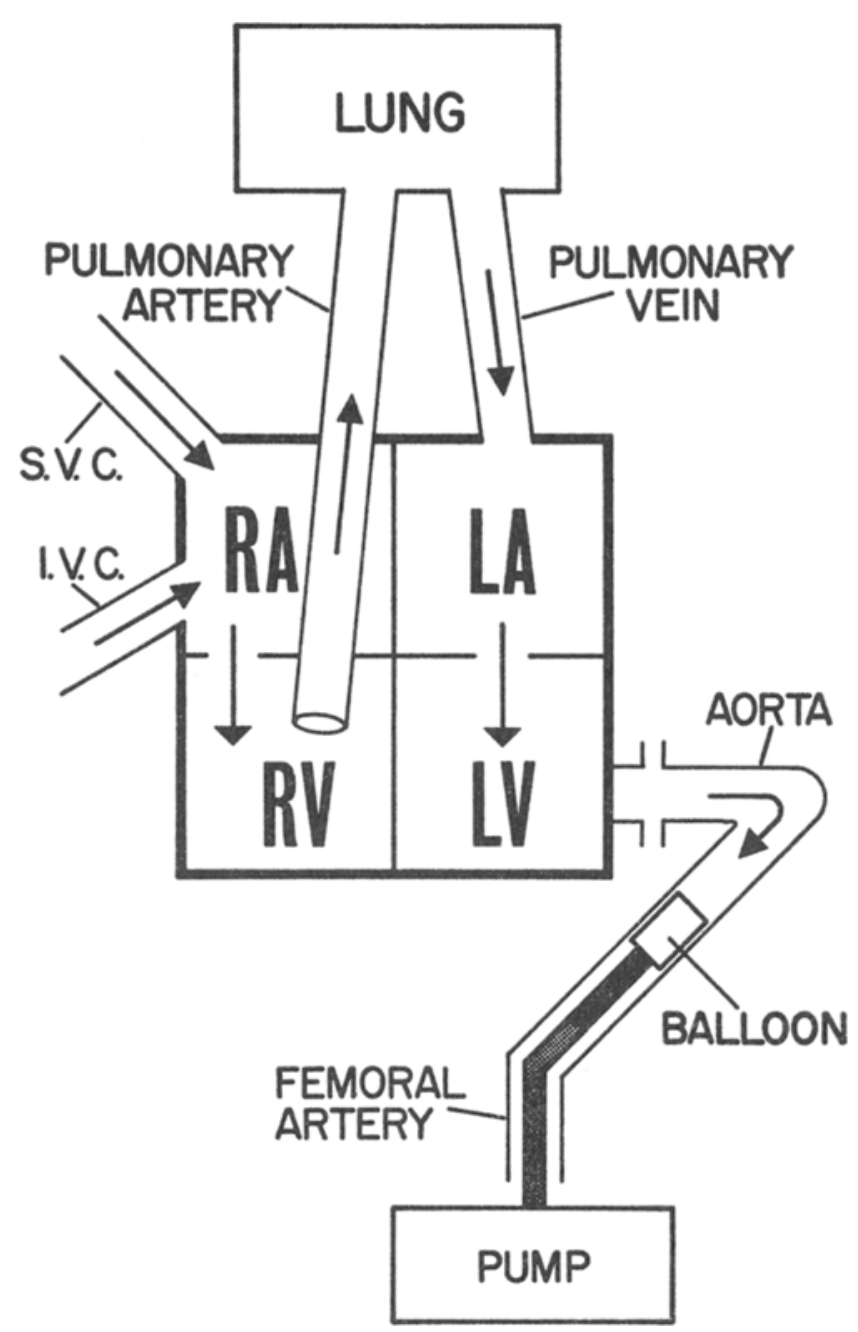

Figure 5. Counter pulsation: balloon in aorta inflates during ventricular diastole, deflates during systole.

(ii) Balloon. A new approach ${ }^{38-40,42}$ to the problem of decreasing the pressure in the aorta during systole and increasing it during diastole has been tried with somewhat more success than the arterio-arterial device. In this method a balloon is placed in the aorta; during diastole the balloon is inflated and just before and during systole it is deflated (Figure 5). The deflation, of course, creates an immediate decrease in pressure and reverse obtains during diastole. As in the arterio-arterial method the decrease in pressure leads to a decrease in left ventricular work and oxygen consumption and the increase during diastole increases coronary flow. Besides being used experimentally it has been used in the clinical field with some success. ${ }^{39}$ Improvement in cardiovascular parameters were noted in using this device similar to that found in using the arterio-arterial system. The 


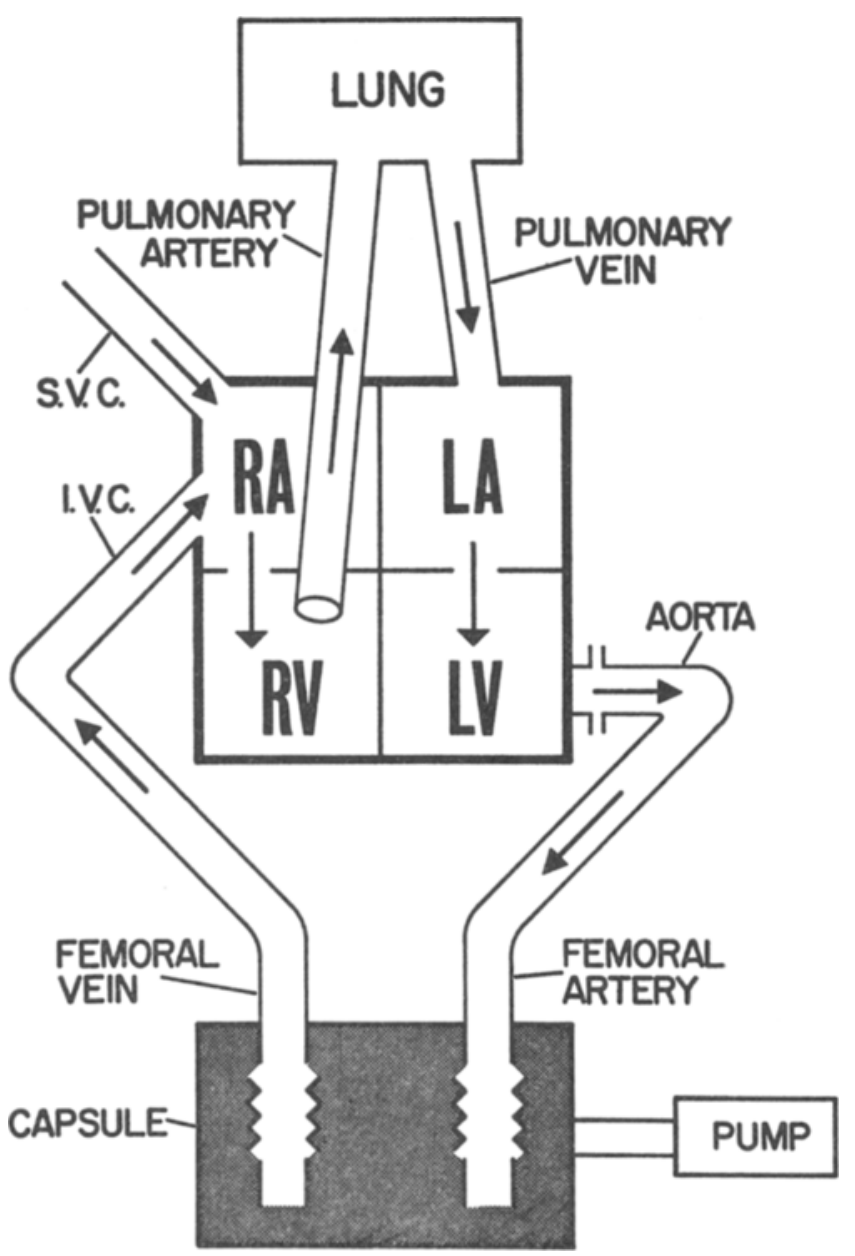

Figure 6. External counterpulsation: capsule surrounding buttocks and legs inflated during ventricular diastole, deflated during systole.

use of carbon dioxide instead of helium for inflation of the balloon leads to fewer problems if the balloon should burst. Intermittent pressure of the balloon on the aorta has been said to cause minimal damage and recently evidence has been put forward to show that this is probably correct. ${ }^{43}$ Although there are few problems with haemolysis, synchronization with the electrocardiogram may still be a problem and any arrhythmias may have to be controlled pharmacologically before this device can be used to full advantage. ${ }^{39}$

(iii) External Counterpulsation. Some of the untoward effects produced by the two devices described can be avoided by this method (Figure 6). It involves enclosing the limbs and buttocks in a capsule and intermittently creating negative and positive pressure to coincide with left ventricular systole and diastole, respectively. ${ }^{44,45}$ The principles involved are similar to the two devices previously dis- 


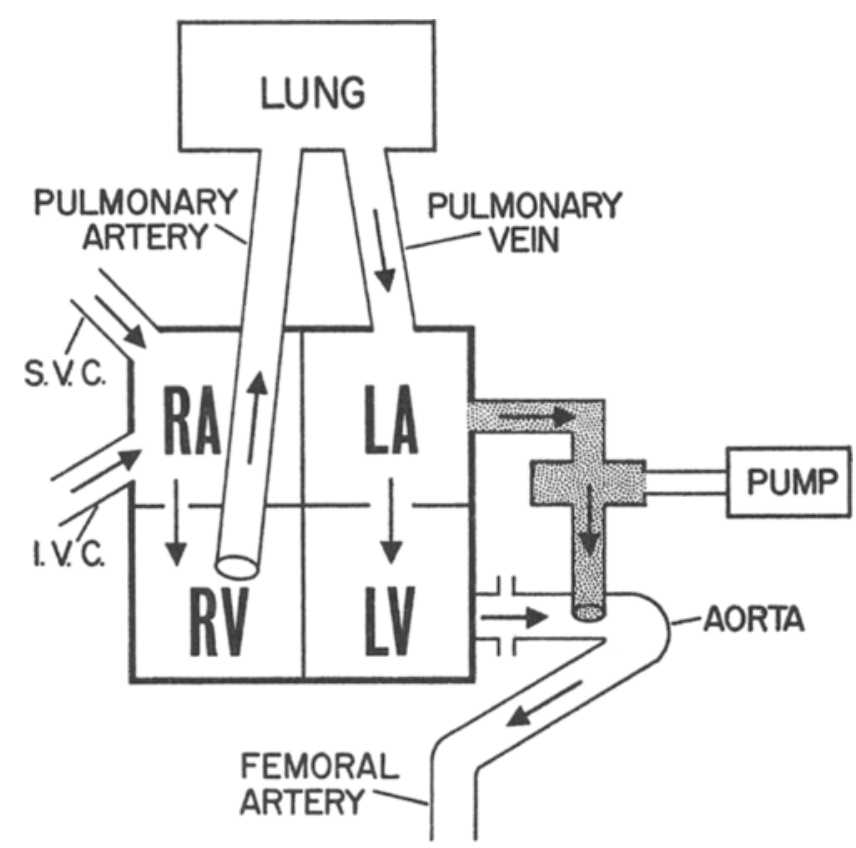

Figure 7. Auxiliary ventricle: in parallel: blood withdrawn from left atrium bypasses left ventricle and is pumped into upper aorta.

cussed. The vacuum causes a dilatation of the arteries and veins of the legs and, therefore, greatly diminishes resistance and increases vascular capacity during ventricular systole. This leads again to decreased left ventricular work and oxygen consumption. The positive pressure during ventricular diastole causes an increase in aortic diastolic pressure and again an increase in coronary flow. Theoretically, its advantage is that no surgical trauma is involved and the patient's blood does not come in contact with any mechanical device. Experimentally ${ }^{44,45}$ in animals and normal volunteers there are definite changes in cardiovascular parameters, correlating well with theoretical considerations. Experience in the clinical field is sparse, but a major problem is that of inducing vascular expansion in a patient who is severely vaso-constricted. Further trials will have to be conducted to assess the merits or otherwise of this device.

All these methods of counterpulsation presume that the left ventricle is producing some output, and therefore, a pulse. If the left ventricle is in such a degree of failure that a pulse is not produced, obviously counterpulsation will be ineffective.

\section{(e) Auxiliary Ventricles}

There have been two types of auxiliary ventricle developed: The "in-parallel" and the "in-series" devices.

(i) In-parallel. Blood is taken from the left atrium and pumped into the upper descending aorta ${ }^{45}$ (Figure 7). The pumping device may be inside or outside the 


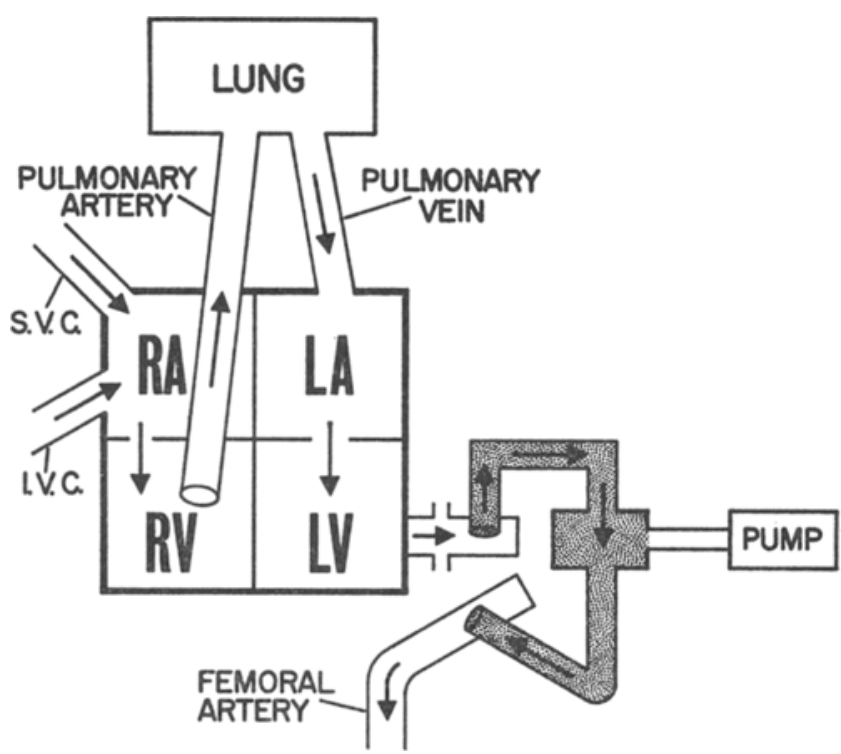

Figure 8. Auxiliary ventricle: in series. Cannulae placed in ligated ends of aorta. Blood pumped from proximal to distal aorta by auxiliary ventricle.

chest cavity. This method decreases the diastolic filling of the left ventricle and therefore the work load of that chamber.

(ii) In-series. This device is attached to the arch of the aorta and the aorta is ligated at this point ${ }^{46,47}$ (Figure 8). During a left ventricular contraction the auxiliary ventricle expands to receive the blood ejected by the left ventricle and during diastole pumps it on down the descending aorta. The working principle is therefore similar to that of the balloon counterpulsation device, i.e. the left ventricle pumps into a low pressure area, but most of the work involved in pumping the blood around the body is performed by the auxiliary ventricle.

Again, these two methods involve a large amount of surgical trauma and depend on an adequate delivery of blood to the left side of the heart. They are therefore of little use in conditions such as massive pulmonary embolism and ventricular fibrillation.

\section{(f) Veno-Arterial Bypass}

In this method both femoral artery and vein are cannulated. Venous blood is delivered to the pump oxygenator through the cannula and arterialized blood is pumped into the femoral artery and therefore passes in a retrograde fashion up the aorta (Figure 9). Some workers have stated that this method of mechanical assistance causes an increase in intraventricular pressure, overdistention and further deterioration in myocardial function. ${ }^{48,49}$ Recently, however, we and others ${ }^{50,51}$ have investigated the haemodynamic changes occuring during venoarterial bypass with the heart in ventricular fibrillation and have found evidence of a retrograde flow from the left ventricle through the pulmonary vasculature 


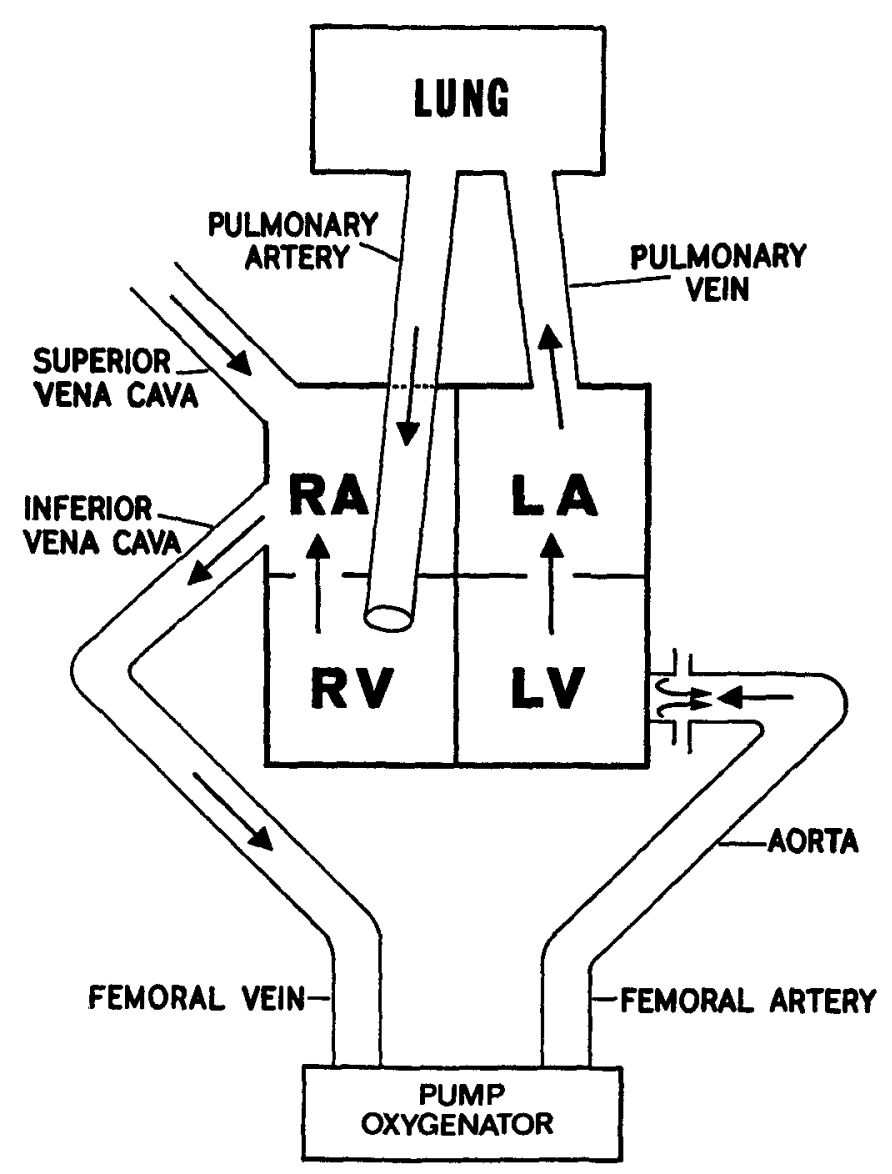

FIgure 9. Veno-arterial bypass: venous blood withdrawn from inferior venae cava and pumped in a retrograde fashion up the aorta.

associated with complete incompetence of the mitral pulmonary and tricuspid valves. Pressure studies have shown that there is no increase in intraventricular pressure; there is, in fact, a marked decrease in all intracardiac pressure with the onset of bypass. The advantage of this method is that there is very little surgical trauma involved and it can support the circulation in the presence of very low cardiac output and even ventricular fibrillation. It is extremely useful in cases of massive pulmonary embolism, relieves the high venous pressure associated with this condition and enables adequate coronary perfusion to take place. It does involve the passage of blood through a mechanical device. However, with advances in the design of pump oxygenators, especially of the membrane variety, many of the problems will become diminished in magnitude. This method has been used with some success clinically in this institution ${ }^{1}$ and with the increasing need for this kind of support and improvement of design a greater proficiency in its use will no doubt be achieved. 


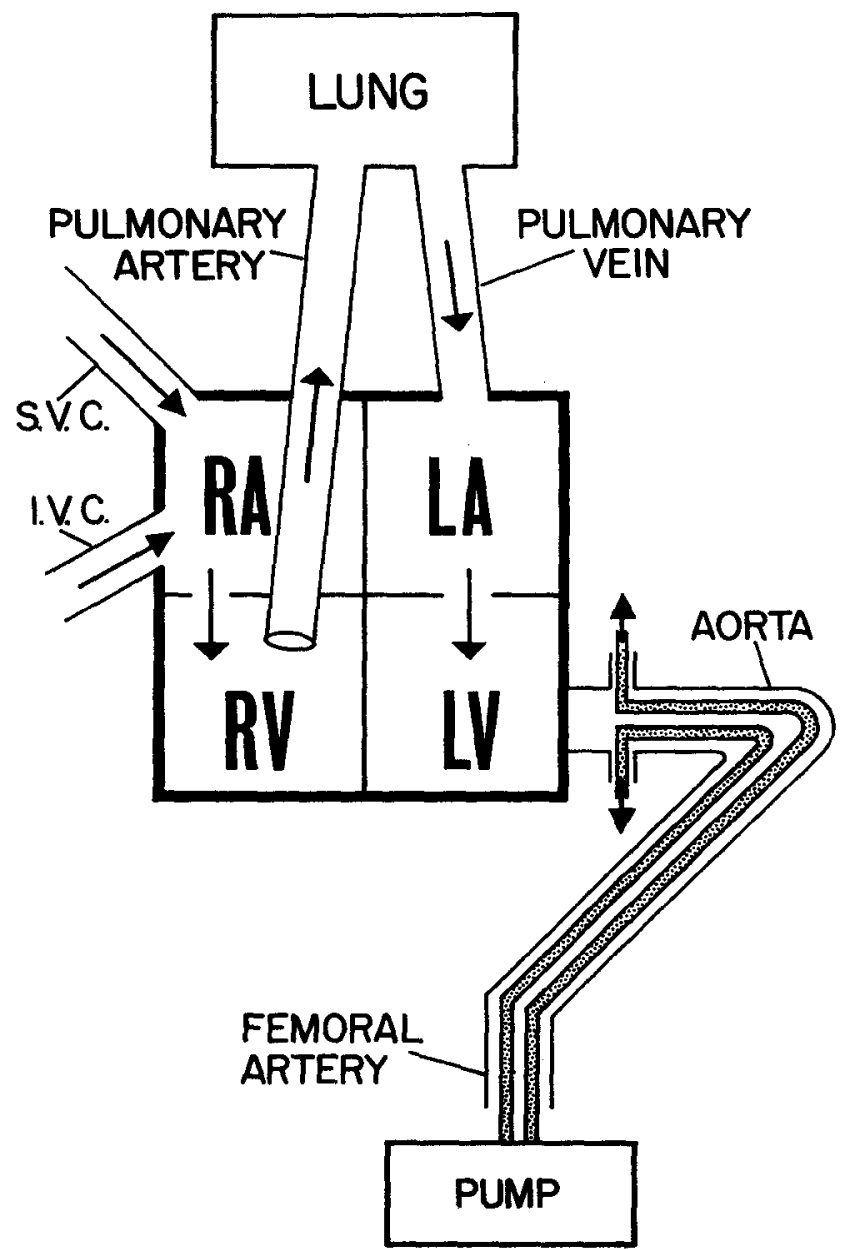

Figure 10. Aorto-coronary perfusion: catheters in coronary arteries: oxygenated blood perfused during ventricular diastole.

\section{Miscellaneous}

\section{(a) Aorto-Coronary Perfusion}

This method does not provide any mechanical support to the circulation. Blood is delivered to the coronary arteries synchronously with ventricular diastole and thereby increases coronary flow ${ }^{52}$ [Figure 10]. Its main advantage is that it involves very little surgical trauma and can be used by the cardiologist, if necessary, in the catheter laboratory.

\section{(b) Veno-Venous and Arterio-Arterial Oxygenation}

These methods only increase the oxygenation of the venous or arterial blood and therefore do not provide any mechanical support to the circulation. Their only use, therefore, may be in lung disease. ${ }^{53,54}$ 


\section{(c) Mechanical Heart}

The legal, moral and medical problems associated with human heart transplantation necessitate the development of a complete mechanical cardiac substitute. Current progress ${ }^{55,56}$ will no doubt make this dream a reality during this decade.

\section{Summary}

The multitude of methods available for mechanical support of the circulation indicate to some extent the inadequacies of present therapy. The major difficulties are associated with engineering, trauma and economics. Any institution that enters into this field of endeavour must be fully aware of the problems involved and the initial depressingly low salvage rate.

\section{Résumé}

Le grand nombre de techniques disponibles pour l'assistance mécanique de la circulation prouve jusqu'à un certain point les insuffisances de la thérapie actuelle. Les principales difficultés relèvent de la conception des ingénieurs de traumatismes et du point de vue économique; toute organisation qui décide d'œuvrer dans ce domaine doit être pleinement consciente des problèmes qui s'y rattachent et du taux peu encourageant de succès.

\section{REFERENCES}

I. BAIrD, R. J. A Practical Approach to Mechanical Circulatory Assistance. Mechanical Assistance of the Circulation. Georg Thieme, Verlag, Stuttgart, West Germany, 103107 (1967).

2. HiLl, J. Brit. J. Dent. Sci., 11: 355 (1868).

3. Macinrosh, R. External Cardiac Massage. Corres. Brit. Med. J., 2: 390 ( 1963 ).

4. Boemm, R. Arch. Exp. Path. Pharmak., 8: 68 (1878).

5. Kouwenhoven, W. B.; Jude, J. R.; \& Knickerbocker, D. G. Closed Chest Cardiac Massage. J.A.M.A., 173: 1064 (1960).

6. Baringer, J. R.; Salzman, E. W.; Wallace, A. J.; \& Friedlich, A. L. External Cardiac Massage. New Eng. J. Med., 265: 62 (1961).

7. Del Guercio, L. R.; Coomaraswamx, A. P.; \& State, D. Cardiac Output and Other Hemodynamic Variables During External Cardiac Massage in Man. New Eng. J. Med., 269: 1398-1404 (1963).

8. Oriol, A. \& Smith, H. J. Hemodynamics Observation During Closed Chest Cardiac Massage. Canad. M. A. J., 98: 841-3 (1968).

9. Thompsen, J. E.; Stenlund, R. R.; \& Rowe, G. G. Intra Cardiac Pressures During Closed Chest Cardiac Massage. J.A.M.A., 205: 116 ( 1968 ).

10. Kilobow, T. \& Bowman, R. By Ventricular Cardiac Assistance Energized by Suction Actuated Recoil of a Single Constricting Rubber Ventricle. Trans. Amer. Soc. Artif. Intern. Organs, 11:57 (1965).

11. Anstadt, G.; Blakemore, W.; \& Baue, A. A New Instrument for Prolonged Mechanical Cardiac Massage. Circulation, 32: suppl. 43 (1965).

12. Anstadt, G. \& Britz, W. Continued Studies in Prolonged Circulatory Support by Direct Mechanical Ventricular Assistance. Trans. Amer. Soc. Artif. Intern. Organs, 14: 297 (1968).

13. Rassman, W. \& Limlehei, C. Long Term Maintenance of Total or Assisted Cardiac Function by Means of an Intra-Corporial Cardiac Compressor. Trans. Amer. Soc. Artif. Organs, 13: 86 (1967).

14. Racitr, A.; Greenfield, A. J.; Skinner, D. B.; Newman, M. H.; \& Rutherford, R. B. Organ Blood Flow Measured by Radionuclide - Labelled Microspheres during Mechanical Ventricular Assistance. Ann. Thor. Surg., 11: 1:43 (1971). 
15. Patrerson, S. W. \& Starling, E. H. On the Mechanical Factors Which Determine the Output of the Ventricle. J. Physiol., 48: 357 (1914).

16. STARLING, E. H. The Linacre Lecture on the Law of the Heart. London and New York, Longman, Green \& Co (1918).

17. Cross, C. E.; Rteben, P. A.; \& Salisbury, P. F. Influence of Coronary Perfusion and Myocardial Oedema on Pressure - Volume Diagram of the Left Ventricle. Am. J. Physiol., 201: 102 ( 1961 ).

18. Sarnoff, S. J. Myocardial Contractiles as Described by Ventricular Function Curves. Physiol. Rev., 35: 107 (1955).

19. Stone, H. L.; Bishop, V. S.; \& Guyton, A. C. Cardiac Function After Embolysation of Coronaries with Microspheres. Am. J. Physiol., 204: 16 (1963).

20. Sarmbury, P. F.; Cross, C. E.; Katsuhara, K.; \& Rieben, P. A. Factors Which Initiate or Influence Oedema in the Isolated Dog's Heart. Circ. Research., 9: 601 (1961).

21. Kilburn, K. H. Hemodynamic Effects of Continuous Postive and Negative Pressure Breathing in Normal Man. Circ. Research, 8: 660 (1960).

22. Hout, J. P. The Effect of Positive and Negative Intra-Thoracic Pressure on Cardiac and Venous Pressure in the Dog. Am. I. Physiol., 142: 594 (1944).

23. Covrnann, A.; Motrey, H. L.; Wenko, L.; \& Richards, D. W. Physiologic Studies of Effects of Intermittent Positive Pressure Breathing on Cardiac Output in Man. Am. J. Physiol., 182: 162 (1948).

24. Braunwalk, E.; Binion, J. T; Morgan, W. L.; \& Sarnoff, S. J. Alteration in Central Blood Volume and Cardiac Output Induced by Positive Pressure Breathing and Counteracted by Metaraminol. Circ. Research, 5:670 (1957).

25. Dfannis, C.; Hall, C. P.; Marino, J. R.; \& Senning, A. Atrial Septal Puncture for Total Left By-pass. Acta Chir. Scandinav., 1, 2, 3: 267 (1962).

26. Swart, H. J. Complete Left Heart By-pass Without Thoracotomy. Thesis, Amsterdam S.O.L. Offsett.

97. Salrsbury, P. F.; Cross, C. E.; Rleben, A.; \& Lewin, R. J. Comparison of Two Types of Mechanical Assistance in Experimental Heart Failure. Circ. Research, 8: 431 ( 1960 ).

28. Schenk, W. G.: Delvi, N. A.; Camp, F. A.; MacDonald, K. F.; Pollack, L.; Gage, A. A.; \& Charnack, W. M. Assisted Circulation. Arch. Surg., 88: 327 ( 1964).

29. Baird, R. J.; Labrosso, C. J.; Lajos, T. Z.; \& Thomas, T. W. Effects of Selective By-pass of the Left Ventricle. Circulation, 27: 835 (1963).

30. Harken, D. International College of Cardiology Meeting, Brussels.

31. Clauss, R. H.; Birtwell, W. C.; Albertal, G.; Lunzer, S.; Taylor, W. J.; Fosberg, A. M.; \& HARKen, D. E. Assisted Circulation. J. Thorac. Card. Surg., 41: 447 (1961).

32. Sarnoff, S. J.; Braunwald, E.; Welch, H. G.; Case, R. B.; Stainsby, W. N.; \& Machuz R. Hemodynamic Determinants of Oxygen Consumption of the Heart with Special Reference to the Tension Time Index. Amer. J. Physiol., 192: 148 (1958).

33. Katz, L. N. Analysis of the Several Factors Regulating the Performance of the Heart. Physiol. Rev., 35: 91 (1955).

34. Robard, S.; Williams, C. B.; Robard, D.; \& Berglund, E. Myocardial Tension and Oxygen Uptake. Circ. Research, 14: 139 (1964).

35. GoldfarB, D. \& Brown, B. G. Dyastatic Augmentation: Circulatory Dynamics Following Coronary Artery Ligation in Dogs. Assistierte Zirkulation, Stuttgart. Georg Thieme, 40 (1967)

36. Birtwell, W. C. \& Soroff, H. S. Synchronous Methods of Assisting the Circulation. Assistierte Zirkulation, Stuttgart. Georg Thieme, 1 (1967).

37. Jacobey, J. A.; Taylor, W. J.; Smith, G. T.; Gorlin, R.; \& Harken, D. E. A New Therapeutic Approach to Acute Coronary Occlusion. Surg. Form, 12: 225 ( 1961 ).

38. Moulopoulos, S. D.; Topaz, S.; \& Kolff, W. J. Diastolic Balloon Pumping in the Aorta a Mechanical Assistance to the Failing Circulation. Amer. Heart J., 63: 669 (1962).

39. Kantrowitz, A.; Tjønnland, F.; Krakower, J.; Butner, A. N.; Phillips, S. J.; Yahr, W. Z.; Shapro, M.; Freed, P. S.; Jarndy, J.; \& Sherman, J. L. Clinical Experience with Cardiac Assistance by Means of Intra-Aortic Phase Shift Balloon Pumping. Trans. Amer. Soc. Artif. Intern, Organs, 14: 344 (1968).

40. Brown, B. G.; Goldfarb, D; Topaz, S. R.; \& Gott, V. L. Diastolic Augmentation by Intra-Aortic Balloon Circulatory Hemodynamics and Treatment of Severe Acute Left Ventricular Failure in Dogs. J. Thorac. Cardiovac. Surg., 53: 789 ( 1967 ).

41. Goldfarb, D. Discussion in Assistiere Zirkulation. Stuttgart. Georg Thieme, 37: (1967).

42. Schilt, W.; Freed, P. S.; Kahill, G.; \& and Kantrowitz, A. Temporary Non-Surgical Intra-Arterial Cardiac Assistance. Trans. Amer. Soc. Artif. Intern. Organs, 13: 322 ( 1967 ). 
43. KAtUBig, C.; Rem, J. D.; \& Kennedy, J. H. Morphologic Results of Intra-Aortic Balloon Pumping in Man. J. Cardiovasc. Surg., 11: 274 (1970).

44. Birtwell, W. C.; Soroff, M. S.; Giron, F.; Fuller, W. B.; Rutz, U.; \& DeGerling, R. A. Synchronous Assisted Circulation. Can. Med. Ass. J., 05: 652 (1966).

45. Ruiz, U.; Soroff, H. S.; Birtwell, W. C.; Many, M.; Giron, F.; \& Deterling, R. A. JR. Assisted Circulation by Synchronous Pulsation of Extramural Pressure. J. Thorac. \& Cardiovasc. Surg., 56: 6 (1968).

46. DeBakey, M.; Liotta, D.; \& HALL, W. Left Heart By-pass Using an Implantable Blood Pump in Mechanical Devices to Assist the Failing Heart. Nat. Acad. Sci., 1966.

47. Kantrowitz, A. Mechanical Support of the Failing Heart, Assistierte Zirkulation, Stuttgart. Georg Thieme, 78 (1967).

48. Tృønnland, S.; Oxuno, T.; \& Kantrowrtz, A. Hemodynamic Studies with Newly Designed Auxiliary Ventricle in Dogs. Trans. Amer. Soc. Artif. Intern. Organs, 8: 306 (1967).

49. Salisbury, P. F.; Cross, C. E.; Rueben, P. R.; \& Lewin, R. J. Comparison of Two Types of Mechanical Assistance in Experimental Heart Failure. Circ. Research, 8: 431 (1960).

50. Salisbury, P. F.; Bow, N.; Lewin, R. J.; \& Rieben, P. A. Effects of Partial and Total Heart-Lung By-pass on the Heart. J. Appl. Physiol., 14: 458 (1959).

51. Proctor, E. Supportive Perfusion. An Experimental Study of its Value in Resuscitation. British J. Surg., 54: 474 (1967).

52. Evans, D., et al. The Effects of Closed Chest Veno-Arterial By-pass with Oxygenation on Cardio-Pulmonary Hemodynamics. J. Thorac. Cardiovasc. Surg., 1971. In Press.

53. Sugrmoto, T.; Sagawa, K.; \& Guyton, A. C. Quantitative Effect of Low Coronary Pressure on Left Ventricular Performance. Jap. Heart J. 9: 46-56 (1968).

54. Schramel, R.; Keilet, C.; Human, A.; \& Creech, O. Full Observations on Veno-Venous Pumping in Mechanical Devices to Assist the Failing Heart. Proc. Nat. Acad. Sci., U.S.A. 1966.

55. Hanlon, C. Arterio-Arterial Perfusion with Oxygenator in Mechanical Devices to Assist the Failing Heart. Proc. Nat. Acad. Sci., U.S.A. 1966.

56. Hall, C. W.; Lrotta, D.; \& DeBakey, M. E. Bioengineering Efforts in Developing Artificial Hearts and Assistors. Amer. J. Surg., 114: 24 (1967).

57. Burns, W. H. \& Loubier, R. J. The Development of an Electro-Hydraulic Inflammable Artificial Heart. Digest of 6 th International Conference of Medical Electronic and Biologic Engineering, Tokyo, Japan. 